\title{
Injuries Due to Wedging of Bicycle Wheels in On-road Tram Tracks
}

\author{
Jaap Deunk ${ }^{1,}$; Annelieke M. K. Harmsen ${ }^{1}$; Casper P. Schonhuth ${ }^{2}$; Frank W. Bloemers ${ }^{1}$ \\ ${ }^{1}$ Department of Trauma Surgery, VU University Medical Center, Amsterdam, The Netherlands \\ ${ }^{2}$ Department of Orthopedic Surgery, VU University Medical Center, Amsterdam, The Netherlands \\ ${ }^{*}$ Corresponding author: Jaap Deunk, Department of Trauma Surgery, VU University Medical Center, Amsterdam, The Netherlands. Tel: +31-204444554, Fax: +31-204444512, E-mail: \\ j.deunk@vumc.nl
}

Received: August 26, 2014; Revised: November 1, 2014; Accepted: November 2, 2014

\begin{abstract}
Background: In cities with trams as public transportation, tram tracks are often on public roads, creating a shared road situation with other road participants like cyclists. Beside the risk of direct collisions, this situation can also lead to bicycle wheels getting wedged in tram tracks, causing cyclists to fall.

Objectives: The aim of this study was to gain more insight in the injury pattern of this trauma mechanism and to draw attention to the risks of the infrastructural situation with on-road tram tracks.

Patients and Methods: A one-year, prospective, observational cohort study was conducted. All patients admitted after presentation to the emergency department of a level 1 trauma center, who got injured because their bicycle wheels got wedged in tram tracks, were included. Data were collected on patient demographics, type of injury and treatment.

Results: Ten patients were included. Six were male. The mean age was 38 years. Six patients required surgery, mostly because of extremity injuries. Mean duration of admission was 4 days. Mean injury severity score was 13 . One patient died as a result of the injuries sustained in the accident.

Conclusions: Tram tracks on public roads are potentially dangerous and can lead to serious injuries and even mortality amongst cyclist. Operative intervention is frequently needed.
\end{abstract}

Keywords:Traffic Accidents; Blunt Injury; Accident Prevention; Accidental Fall

\section{Background}

The Netherlands is known as the country with the highest density of cyclists in the world. The approximately 17 million inhabitants own over 18 million bicycles and approximately $25 \%$ of all commutes are done by bicycle (1). While cycling in the Netherlands has been a common means of transport for decades already, recently popularity seems to increase internationally as well. Cycling has many advantages like the improvement of health and being environmentally friendly. One disadvantage is that cyclist is vulnerable in traffic (2). In the Netherlands, approximately 70000 patients are treated annually in an emergency department (ED) after a bicycle injury. Of these patients, almost 10,000 are admitted to a hospital and approximately two hundred patients die as a result of their injuries (1). Therefore, many efforts are made to prevent injuries amongst cyclists, including special safety programs for cyclists and creating a safer infrastructure (2-5). At the same time, transportation by tram has likewise become increasingly popular because of its excellent passenger safety, environmental benefits and relief of traffic congestion. In many cities across the world, trams have been added to an already existing infrastructural situation, resulting in tram tracks on the public road. On- road tram tracks, however, are thought to increase the number of accidents for other road participants, including cyclists (6-9). Literature shows that cyclist is the largest group to sustain injuries due to trams $(7,8)$. Obvious consequences are direct collisions between trams and cyclists (10). In contrast to direct collisions, cycling crashes as a result of bicycle wheels getting wedged in the tram tracks causing the cyclists to fall are less known. In current literature, little has been published on this mechanism of trauma (8).

\section{Objectives}

To gain more insight in the injury pattern of this trauma mechanism and to draw attention to the risks of the on-road tram tracks, we aimed to describe a cohort of patients who got injured because their bicycle wheels got wedged in tram tracks.

\section{Patients and Methods}

Between October 2012 and December 2013, all patients who got injured after a fall with a bicycle because their wheels got wedged in on-road tram tracks and consequently referred to the emergency department of a level I trauma center, were included in this prospective cohort

Copyright (c) 2014, Kashan University of Medical Sciences. This is an open-access article distributed under the terms of the Creative Commons Attribution-NonCommercial 4.0 International License (http://creativecommons.org/licenses/by-nc/4.0/) which permits copy and redistribute the material just in noncommercial usages, provided the original work is properly cited. 
DeunkJet al.

\begin{tabular}{|c|c|c|c|c|c|c|}
\hline Pt & Gender & Age, $y$ & Injury Description & Treatment & DoA & ISS \\
\hline $\mathbf{1}$ & $\mathrm{F}$ & 28 & grade 2 open tibia fracture & plate osteosynthesis & 14 & 9 \\
\hline 2 & M & 63 & severe TBI: epi-/subdural haematoma & craniotomy & $3^{b}$ & 25 \\
\hline 3 & $\mathrm{~F}$ & 65 & bimalleolar ankle fracture & plate osteosynthesis & 11 & 9 \\
\hline 4 & $\mathrm{~F}$ & 29 & mild TBI, 1 rib fracture & observation on ward & 2 & 18 \\
\hline 5 & M & 58 & 4 rib fractures & observation on MCU & 2 & 9 \\
\hline 6 & M & 60 & severe TBI: epi-/subdural haematoma & observation on MCU & 3 & 25 \\
\hline 7 & $\mathrm{~F}$ & 26 & grade 1 open distal humeral fracture & plate osteosynthesis & 4 & 9 \\
\hline 8 & M & 28 & maxillofacial fracture. Mild TBI & plate osteosynthesis & 2 & 10 \\
\hline 9 & M & 11 & distal radial fracture & plate osteosynthesis & 1 & 9 \\
\hline 10 & M & 16 & light TBI, leg wound & observation on ward & 1 & 5 \\
\hline
\end{tabular}

a Abbreviations: Pt, patient; M, male; F, female; TBI, traumatic brain injury; DoA, duration of admission; ISS, injury severity score; MCU, medium care unit.

$\mathrm{b}$ This patient died after 3 days.

study. Patient demographics (age and gender), type of injury, injury severity scores (ISS), duration of hospital admission (in days) and treatment were collected.

\section{Results}

During the study period ten, patients were admitted to our hospital because of their injuries sustained after cycling crashes as a result of bicycle wheels getting wedged in on-road tram tracks. All patients were local inhabitants. Six out of ten patients were male. The mean age was 38 years. Six patients required surgery: four due to injuries to the extremities, two due to neurotrauma or maxillofacial injuries. Five patients had brain injury, of which two were severe. Mean duration of admission was four days, ranging from one to fifteen days. Mean injury severity score was thirteen, ranging from five to 25 . One patient died as a result of the injuries sustained. This patient suffered severe neurotrauma with multiple epidural and subdural haematomas. Despite decompressive craniotomy executed by the neurosurgeon, the patient died three days later as a consequence of his severe neurological injuries. Data per patient are shown in Table 1.

\section{Discussion}

Increased environmental awareness and progressive congestion of city centers by motor vehicles have led to a global search for alternative types of transport $(11,12)$. This has led to an increased usage of both bicycles and public transport. Trams have regained popularity in many cities across Europe and the US because of their reliability, their ability to safely transport large amounts of people and their small environmental footprint (13). However, due to spatial limitations of the dense city centers, this puts a burden on the existing road network. Thus many tram tracks are on public roads and trams have to share the road with other road participant like cyclists. Apart from the apparent risk of a direct collision between a tram and other road participants, there is a less obvious risk that especially concerns cyclists. When tram tracks are levelled with the tarmac, there is a gutter of a couple inches deep within the road surface, in which the narrow bicycle wheels can get wedged easily. When either the front or back wheel of a bicycle gets wedged in one of these gutters, the bicycle is forced in one direction whilst the body moves in the other, causing a cyclist to fall. This study shows that this mechanism of trauma is a relatively frequent recurring phenomenon in our hospital with at least ten severe cases in one year. However, the true incidence and size of the problem remain unclear. This study is not suitable for determining true incidence rates for this type of trauma, seeing as there are five other hospitals in the surrounding area, which all receive patients with similar types of injury. Furthermore, only patients who had been admitted to our hospital have been included. Patients who were discharged from the ED or treated in the out-patient clinic were not included. The actual number of casualties due to this mechanism of trauma per year will therefore be considerably higher within the depicted population. What this study does show is that tram tracks as a part of the public road can lead to potentially dangerous situations for cyclists. Many injuries were severe and required an operative intervention. One patient died as a consequence of his injuries. Although this injury mechanism with on-road tram tracks is very dependent on the local traffic situation, the results of this study might be relevant for other international cities with on-road tram tracks or for cities considering trams as a part of their local transport infrastructure. Awareness of the potential danger of on-road tram tracks is essential for policy makers. To reduce the number of casualties and to increase the safety of bicyclists, roads for cyclists and trams should be segregated (2). If this is cannot be realized, another possible intervention could be the placement of rubber linings within the tram gutter, making it difficult for bicycle wheels to get trapped in them (14). 
Additionally, more attention could be given to education and warning of cyclists. Cameron et al. showed a sharp decline in the level of cycling injuries after a period of local media attention (8). Finally, it is not obligated to wear helmets whilst cycling in the Netherlands. Though the mandatory use of helmets is still under debate, it is thought to reduce the incidence and the severity of brain injuries amongst cyclists $(2,15)$. However, helmet use will have no effect on extremity injuries, which comprised a substantial amount of injuries in our population.

In conclusion, tram tracks on public roads are potentially dangerous and can lead to serious injuries and even mortality amongst cyclist. Extremity and neurological injuries are the most common injuries and frequently need an operation. Awareness of the potential danger of on-road tram tracks for cyclists is essential. Alteration of infrastructural situations or other preventive measures might decrease the incidence of these injuries and should therefore be considered.

\section{Authors' Contributions}

Study concept and design: Jaap Deunk. Analysis and interpretation of data: Jaap Deunk. Drafting of the manuscript: Jaap Deunk and Annelieke M. K. Harmsen. Critical revision of the manuscript for important intellectual content: Jaap Deunk, Annelieke M. K. Harmsen, Casper P. Schonhuth and Frank W. Bloemers. Statistical analysis: Jaap Deunk and Annelieke M. K. Harmsen. Study supervision: Jaap Deunk and Frank W. Bloemers.

\section{Funding/Support}

This study was approved by the Medical Ethics Review Committee of the VU University Medical Center, Amsterdam, The Netherlands.

\section{References}

1. Veiligheid C. Fietsongevallen. 2011. Available from: http://www. veiligheid.nl/csi/veiligheidnl.nsf/0/B6B52DF63B9F82ABC1257BD4 00480EF8/\$file/Factsheet\%20fietsongevallen\%202005-2009.pdf.

2. Wegman F, Zhang F, Dijkstra A. How to make more cycling good for road safety? Accid Anal Prev. 2012;44(1):19-29.

3. De Rome L, Boufous S, Georgeson T, Senserrick T, Richardson D, Ivers R. Bicycle crashes in different riding environments in the Australian capital territory. Traffic Inj Prev. 2014;15(1):81-8.

4. Harris MA, Reynolds CC, Winters M, Cripton PA, Shen H, Chipman $\mathrm{ML}$, et al. Comparing the effects of infrastructure on bicycling injury at intersections and non-intersections using a case-crossover design. Inj Prev. 2013;19(5):303-10.

5. Richmond SA, Zhang YJ, Stover A, Howard A, Macarthur C. Prevention of bicycle-related injuries in children and youth: a systematic review of bicycle skills training interventions. Inj Prev. 2014;20(3):191-5.

6. Hedelin A, Bjornstig U, Brismar B. Trams--a risk factor for pedestrians. Accid Anal Prev. 1996;28(6):733-8.

7. Vandenbulcke G, Thomas I, Int Panis L. Predicting cycling accident risk in Brussels: a spatial case-control approach. Accid Anal Prev. 2014;62:341-57.

8. Cameron IC, Harris NJ, Kehoe NJ. Tram-related injuries in Sheffield. Injury. 2001;32(4):275-7.

9. Unger R, Eder C, Mayr JM, Wernig J. Child pedestrian injuries at tram and bus stops. Injury. 2002;33(6):485-8.

10. Mitra B, Al Jubair J, Cameron PA, Gabbe BJ. Tram-related trauma in Melbourne, Victoria. Emerg Med Australas. 2010;22(4):337-42.

11. Karanasiou A, Viana M, Querol X, Moreno T, de Leeuw F. Assessment of personal exposure to particulate air pollution during commuting in European cities--recommendations and policy implications. Sci Total Environ. 2014;490:785-97.

12. Rojas-Rueda D, de Nazelle A, Teixido O, Nieuwenhuijsen MJ. Health impact assessment of increasing public transport and cycling use in Barcelona: a morbidity and burden of disease approach. Prev Med. 2013;57(5):573-9.

13. PTEG. What modern trams can do for cities.; 2006.

14. Newstix. Velofreundliche Tramgleise-Testfahrten positiv, aber Material noch nicht dauerhaft. 2014. Available from: http://www.newstix.de/index.php?.

15. Cripton PA, Dressler DM, Stuart CA, Dennison CR, Richards D. Bicycle helmets are highly effective at preventing head injury during head impact: head-form accelerations and injury criteria for helmeted and unhelmeted impacts. Accid Anal Prev. 2014;70:1-7. 